\title{
Letter to the Editor concerning "Postoperative outcomes in distal hypospadias: a meta-analysis of Mathieu and tubularised incised plate repair methods for the development of urethrocutaneous fistula and urethral stricture"
}

\author{
V.V. S. Chandrasekharam ${ }^{1}(1) \cdot$ Ramesh Babu $^{2}$ \\ Accepted: 6 February 2022 / Published online: 16 February 2022 \\ (c) The Author(s), under exclusive licence to Springer-Verlag GmbH Germany, part of Springer Nature 2022
}

\section{Dear Editor}

We read with interest the article by Winberg et al. [1]. The authors performed a meta-analysis comparing the outcomes of Mathieu and tubularized incised plate (TIP) techniques for distal hypospadias repair. Specifically, the authors analysed two complications, namely urethrocutaneous fistula and urethral stricture. We like to congratulate and thank the authors for their thorough scientific methodology. Their meta-analysis is likely to serve as a reference for any future article on Mathieu and TIP techniques. However, we found an error in their paper which we think needs clarification.

Winberg et al. mentioned in the discussion section of their article that Mathieu repair results in the hairy urethra in the long term [1]. Interestingly, they did not mention this finding anywhere in their results of extensive meta-analysis of the available literature on Mathieu's operation! To support their statement, Winberg et al. referenced a review article [2] by Cimador et al. (reference 34 of the article by Winberg et al.). However, we read the article by Cimador et al. [2] thoroughly but could not find any reference to Mathieu repair causing a hairy urethra in the long term! We contacted Dr. Cimador, the primary author of that article [2] by email to clarify regarding this matter; Dr. Cimador very promptly replied back and confirmed that their article had been misquoted and they have never seen hairy urethra after a Mathieu operation.

Mathieu's technique is a popular operation for the repair of both primary and salvage distal hypospadias repairs.

V. V. S. Chandrasekharam vvsssekharam@gmail.com

1 Hypospadias Clinics, Ankura Hospitals for Women and Children, Hyderabad, India

2 SRIHER, Chennai, India
We failed to find any reference in the literature about hairy urethra as a complication of Mathieu operation, including a meta-analysis published in 2012 [3]. Thus, we feel it is important to clarify this mistake by Winberg et al. so that their paper, which is a seminal paper likely to be referenced by any future authors writing about Mathieu operation, is itself not further misquoted again and again in this context.

Funding None.

\section{Declarations}

Conflict of interest The authors declare that they have no conflict of interest.

Ethical approval N/A.

Informed consent N/A.

\section{References}

1. Winberg H, Arnbjornsson E, Anderberg M, Stenstrom P (2019) Postoperative outcomes in distal hypospadias: a meta-analysis of Mathieu and tubularised incised plate repair methods for the development of urethrocutaneous fistula and urethral stricture. Pediatr Surg Int 35:1301-1308

2. Cimador M, Vallasciani S, Manzoni G, Rigamonti W, De Grazia E, Castagnetti M (2013) Failed hypospadias in pediatric patients. Nat Rev Urol 10:657-666

3. Wilkinson DJ, Farrelly P, Kenny SE (2012) Outcomes in distal hypospadias: a systematic review of Mathieu and tubularised incised plate repairs. J Pediatr Urol 8:307-312

Publisher's Note Springer Nature remains neutral with regard to jurisdictional claims in published maps and institutional affiliations. 